\title{
Rapid and Accurate Mitochondrial DNA Analysis in Amino Glycoside Sensitive Patients
}

\section{Torres-Ruiz NM and Meza G*}

Division of Neuroscience, Institute of Cellular Physiology, National Autonomous University of Mexico, Mexico DF 04510, Mexico

\begin{abstract}
The use of Restriction Fragment Length Polymorphism to assess the position of mutation in nuclear or mitochondrial DNA is very common but the effectiveness of this methodology is limited and expensive since it utilizes many reagents that are not easy to acquire. We propose the use of a Denaturing Gradients Gel Electrophoresis to analyze the presence of mutation T1189C in the 12S rRNA region of human mitochondrial DNA, formerly detected by nucleotide sequence analysis, in order to develop an optimized method that would allow the simultaneous detection of this mutation in several patient mitochondrial DNA and further finding the relationship of its presence with sudden deafness produced by hypersensitivity to aminoglycoside antibiotic treatment. The technique was improved optimizing the denaturing gradient gel electrophoresis parameters, such as optimum temperature, voltage, concentration of denaturing agents and time for carrying out the method, which allowed us to precisely distinguish whether there has been a change in the sequence of a given sample, analyzing a wild type mitochondrial 12S rRNA against the patient sample simultaneously, by simply observing the differences in running time of a band in which mutation is present, and corroborated by sequence analysis. The application of the technique to samples of various patients at the same time would be very valuable to assess the presence of the mutation prior to treatment of a given infection is started and to recommend the use of an alternative therapeutic agent innocuous for the inner ear.
\end{abstract}

Keywords: Mitochondrial 12S rRNA gene; DGGE; T1189C; Aminoglycosides; Sudden deafness

Abbreviations: AG: Aminoglycoside; RFLP: Restriction Fragment Length polymorphism; DGGE: Denaturing Gradient Gel Electrophoresis

\section{Introduction}

The ototoxicity of aminoglycosideantibiotics (AG) such as streptomycin or gentamicin has been recognized since early times of their development. Damage to the ear includes the sensory cells of the vestibular and the hearing portion of the inner ear, in sequence, and it is established slowly along treatment (about 6 months). However, there are some instances in which hearing loss appears at early time of therapeutics (from 10 days to a month) [1,2]. This action is attributed to the presence of genetic alterations in the mitochondrial DNA $[3,4]$.

These AG are amply used in the clinics of underdeveloped countries, especially in newborns when etiology of the infection is unknown. Therefore it is of upmost importance to determine the genetic predisposition of an individual to develop deafness before they receive AG treatment. One method routinely used to assess such predisposition is to study the segment of mitochondrial DNA suspected to carry a nucleotide change, by PCR and restriction Fragment Length polymorphism (RFLP) and further analysis of sequence by automatic methodology. However, the effectiveness of this method is limited and expensive since it requires a repertoire of enzymes to carry out the analysis.

Therefore, we propose the use of a Denaturing Gradient Gel Electrophoresis (DGGE), first described for the use in environmental microbiology to analyze changes in the composition of bacterial populations of $16 \mathrm{~S}$ rRNA specific nucleotide [5] to determine the presence of the point mutation described earlier by our group (T1189C) in the 12S rRNA mitochondrial gene in individuals with deafness produced by chronic AG treatment [6]. This technique has not been very extensively used in the past in human studies. A search in the database of NCBI with keywords "DGGE and mitochondria" revealed 17 results, of which only 6 are in humans. Among them, 4 studied genes of tRNA, one the hypervariable region 1(HV1) and the last one scanned the whole DNA of mitochondria. Our work would be the first report to describe that a point mutation in the $12 \mathrm{~S}$ rRNA gene of human mitochondria analyzed by DGGE may be associated with aminoglycoside-induced hearing loss when its presence is confirmed in a large group of patients.

With this methodology it would be possible to analyze several samples simultaneously without the need to invest in different reagents for each position. The reported conditions used for mitochondrial DNA vary greatly i.e., the time of running the sample from $4-18 \mathrm{~h}$, voltage from 65 to $150 \mathrm{~V}$ and broad or narrow concentration spans of denaturing gradient agents (urea/formamide) [7,8,9].The efficiency of DGGE is also influenced by factors such as primer design for PCR, gel composition, size of DNA fragment, its $\mathrm{G}+\mathrm{C}$ content and electrophoretic conditions [10,11].

Accordingly, given the amount of variables to be taken into account, establishment of optimal conditions for the study is complex and it depends on the known sequence of the normal region in which the detection of nucleotide changes is pursued. Thus, some parameters to determine would be: the length of primers and conditions for PCR amplification, combination of denaturing gradients, voltage, time of

*Corresponding author: Graciela Meza, Division of Neuroscience, Institute of Cellular Physiology, National Autonomous University of Mexico, Apartado Postal 70-253, 04510, Mexico, Tel (52) 56-22-55-85; Fax (52) 56-22-57-47; E-mail: gmeza@ifc.unam.mx

Received February 08, 2012; Accepted March 21, 2012; Published March 23 , 2012

Citation: Torres-Ruiz NM, Meza G (2012) Rapid and Accurate Mitochondrial DNA Analysis in Amino Glycoside Sensitive Patients. Biochem \& Anal Biochem S3-002. doi:10.4172/2161-1009.S3-002

Copyright: (c) 2012 Torres-Ruiz NM, et al. This is an open-access article distributed under the terms of the Creative Commons Attribution License, which permits unrestricted use, distribution, and reproduction in any medium, provided the original author and source are credited. 
carrying out the sample and temperature used. We found that using a given primer with a GC-clamp added to its $5^{\prime}$ end, denaturing ureaformamide of $20-40 \%$, at $65^{\circ} \mathrm{C}$ and $210 \mathrm{~V}$ during only 4 hours would be the optimal conditions for detection of the T1189C mutation in the human mitochondrial $12 \mathrm{~S}$ rRNA and allows the independent analysis of a number of individual samples under study. We hereby describe the experimental approach and the results obtained.

\section{Material and Methods}

This technique was performed in 3 mitochondrial DNA samples of one normoacusic patient without $\mathrm{T} 1189 \mathrm{C}$ mutation and two hypoacusic treated with aminoglycosides formerly selected at the Instituto Nacional de Enfermedades Respiratorias, México and reported earlier [6]. Primers for amplification around the 1189 region were designed on the basis of the sequence reported by Andrews et al [12] corresponding to position 1071-1096 and 1282-1303 (Table 1). DNA extraction and PCR technique was essentially the same as described in Meza G et al, [6], except that annealing was performed at $55^{\circ} \mathrm{C}$ for GC-clamp for 30 seconds and final extension for $5 \mathrm{~min}$ at $72^{\circ} \mathrm{C}$. Purification of amplified fragment and analysis and alignment of sequence were performed in duplicate for each sample as earlier described [6].

A basic technique for analyzing each DNA fragment with DGGE was performed according to a method described by Myers et al. $[13,14]$ and depending on the results, variations were introduced as described in Table 2. In short: PCR-amplified fragments were analyzed by electrophoresis on $7.5 \%$ polyacrylamide gels containing an increasing denaturing gradient from $0 \%-100 \%$ (100\% denaturant is $7 \mathrm{M}$ urea and $40 \%$ (vol/vol) deionized formamide). The gel was run in 1X Buffer of Tris/Acetic Acid/EDTA at a constant temperature and its effects were studied in a range from 60 to $75^{\circ} \mathrm{C}$, voltage from 150 to $210 \mathrm{~V}$ during 4 to 6.5 hours. Electrophoresis was carried out using the electrophoresis C.B.S Scientific System, after which gels were stained for 20 min with SYBR-Green (Invitrogen) and photographed with a UV transilluminator using a digital camera. The repeatability was studied 3 times with independent PCR samples and identification of

\begin{tabular}{|l|l|}
\hline Name & Sequence \\
\hline $1071 \mathrm{FW}$ & $5^{\prime}$ tgggattagataccccactatgctt $3^{\prime}{ }^{*}$ \\
\hline $1255 \mathrm{RV}$ & $5^{\prime}$ 'ttgctgaagatggcggtatata $3^{\prime}$ \\
\hline $1207 \mathrm{RV}$ & $5^{\prime}$ 'tctgtaatcgataaaccccgatc $3^{\prime}$ \\
\hline $1282 \mathrm{RV}$ & $5^{\prime}$ gatgaaggctacaaagtaagc $3^{\prime}$ \\
\hline (GC-clamp) & $5^{\prime}$ ' gcgggcggcgcggggcgcgggcagggcggcggggggcgggc 3' \\
\hline
\end{tabular}

*to which the 40 nucleotide GC-clamp is attached to its 5 'end. FW: Forward, RV: Reverse

Table 1: Sequence of oligonucleotides used for PCR amplification of mutation T1189C of the $12 \mathrm{~S}$ rRNA gene.

\begin{tabular}{|c|c|c|c|}
\hline Pair Primers & Gradient & $\begin{array}{l}\text { Temperature,/ } \\
\text { Voltage/Time }\end{array}$ & Results \\
\hline 1071FW-1282RV & \multirow{3}{*}{$\begin{array}{l}10-100 \%, 10-40 \% \\
20-40 \%, 25-35 \% \\
40-80 \% \text { and } \\
70-90 \% \text { (each) }\end{array}$} & \multirow{6}{*}{$\begin{array}{l}60 \text { to } 70^{\circ} \mathrm{C} \\
150-220 \mathrm{~V} \\
4 \text { to } 6.5 \mathrm{~h}\end{array}$} & \multirow{3}{*}{$\begin{array}{l}\text { Never increased the } \\
\text { difference between the } \\
\text { mutant and wild sequence } \\
\text { migration (Fig. 1A) }\end{array}$} \\
\hline 1071FW-1207RV & & & \\
\hline 1071FW-1255RV & & & \\
\hline $\begin{array}{l}\text { GC107FW1- } \\
\text { 1282RV }\end{array}$ & \multirow{3}{*}{$\begin{array}{l}10-40 \text { and } 20-40 \% \\
\text { (each) }\end{array}$} & & \multirow{3}{*}{$\begin{array}{l}\text { Better difference in the } \\
\text { pattern migration between } \\
\text { the sequences was at } \\
65^{\circ} \mathrm{C}, 210 \mathrm{~V} \text { and } 4 \mathrm{~h} \text {. (see } \\
\text { Fig. } 1 \mathrm{C} \text { ) }\end{array}$} \\
\hline $\begin{array}{l}\text { GC107FW1- } \\
\text { 1207RV }\end{array}$ & & & \\
\hline $\begin{array}{l}\text { GC107FW1- } \\
\text { 1255RV }\end{array}$ & & & \\
\hline
\end{tabular}

FW-forward, RV- reverse GC tailed oligonucleotide

Table 2: Experimental conditions used to detect and optimize the detection of T1189C site of 12S rRNA mitochondrial gene
T1189C mutation by DGGE was confirmed by sequencing. Samples of patients analyzed rendered the same results regardless the day of experiment or experimental conditions.

\section{Results and Discussion}

DGGE is a great tool because it allows analyzing and comparing different sequences even if there is only one nucleotide change; it enables accurate molecular diagnosis at relatively low cost and there are almost no possibilities for misinterpretation. Therefore for us, the above is especially valuable for the screening of various mutations present at $12 \mathrm{~S}$ rRNA mitochondrial gene. The pivotal point of DGGE is that the Tm of each fragment must necessarily exceed its melting point. The denaturation of DNA fragments occurs due to temperature and chemical agents (urea and formamide) present in the gel during electrophoresis; the difference in denaturant concentration required for DNA strand separation allows to visualize a differential migration between fragments after a dying technique $[7,10,13,14]$.

In our case, the efficiency of DGGE was influenced by primer design, gel composition, size of DNA fragment, $\mathrm{G}+\mathrm{C}$ content of fragment and electrophoretic conditions $[10,11]$. In order to obtain the optimum condition for a rapid and best detection of mutation T1189C it was experimentally analyzed using narrow and broad ranges of denaturing gradient, different temperatures and increasing the voltage to reduce running time.

\section{Application of GC-clamp in migration behavior}

To facilitate the detection of mutations in the higher melting domain, it has been recommended to introduce a GC-rich fragment (GC-clamp) at the 5'end of oligonucleotide and proceed to fragment amplification. In the GC-clamped PCR-fragment, the Tm is reduced and this alters its melting characteristics allowing the detection of mutations in the melted part thereby increasing the sensitivity of DGGE method and helping to visualize a difference of migration pattern $[10,13]$. Taking this claim into account, we have attached a $40 \mathrm{bp}$ GC-clamp to PCR fragment to see if migration behavior could change and a better detection could be achieved. Under DGGE standard conditions $[13,14]$, using a GC clamped fragment in PCR, T1189C containing fragment migrated further in the gel than the unclamped PCR oligonucleotide amplified fragment, thereby, allowing us to clearly distinguish where the mutation was located (See Figure 1.)

\section{Optimization of electrophoretic behavior by temperature} and denaturing gradient

Denaturing gradient gel electrophoresis is based on differences in melting behavior of double-stranded DNA fragments in a gradient with an increasing concentration of urea and formamide. For that reason, we used different gradients in the electrophoresis and obtained the best gradient that allowed us to identify the mutation. When a gradient $10-$ $100 \%$ was used, we could not obtain any difference between bands (the normal individual and mutation bearing DNA) even using different and higher temperature ranges (data no shown), therefore, we decided to use less broad gradients. We started using $10-40 \%, 25-35 \%, 40$ $80 \%$ and $70-90 \%$ but there was no difference regardless of condition used. Most of the fragments stopped at around 20 and 30\%, hence we decided to use a narrower gradient of $20-40 \%$ and the migration pattern improved, therefore the denaturing gradient where the fragments stopped in the migration is key and very important for determining the best denaturing gradient to observe differences in a migration pattern.

Urea and formamide are keys in DGGE and the effect of 
temperature can improve differences of migration patterns among different sequences. Temperature is an easily adjustable parameter that can lead to increased resolution, achieving complete melting and reducing running time. As mentioned above, the detection of T1189C was only using GC-clamped PCR fragment but it was necessary to increase temperature from $60^{\circ} \mathrm{C}$ to $65^{\circ} \mathrm{C}$, to observe a differential running time in the $\mathrm{T} 1189 \mathrm{C}$ and the normal sequence bearing sample. In addition, using a lower percentage of polyacrylamide (7.5\%) and a higher voltage allows that fragments to run faster and reach their melting conditions earlier in the gel. Figure $1 \mathrm{C}$ demonstrates that at an optimum temperature of $65^{\circ} \mathrm{C}$, separation of the bands occurs earlier in the gel reducing the electrophoresis to only $4 \mathrm{~h}$, meanwhile at a temperature of $60^{\circ} \mathrm{C}$ the bands migrate to reach a distance almost to end of the gel (Figure 1B). The voltage used plays an important role here too because under standard conditions it has been managed at $100 \mathrm{~V}$ with the purpose to obtain sharper bands but it requires DGGE to run overnight $[7,8,15]$. In our study we increased the voltage from 150 to $220 \mathrm{~V}$ for 4 to $6.5 \mathrm{~h}$ and we concluded that a voltage of $210 \mathrm{~V}$ was the optimum because it allows separation between the fragments within a reasonable time (4 hours) and render sharper bands.

\section{Precision, sensibility and specificity of method}

The fidelity and specificity of PCR amplification is especially important to reduce errors in analysis of mutations; therefore, we substituted a conventional Thermus aquaticus DNA polymerase (Taq) for a Phusion High-Fidelity DNA polymerase, whose error rate is approximately 50 -fold lower than Taq (Manufacture indications). Also, particularly in mitochondrial DNA analysis it is very important to determine whether the mutations are heteroplasmic or homoplasmic because the former is present at higher frequency of the latter and it can be rendering a single nucleotide "mismatch" [11]. Sensitivity of DGGE previously reported in other studies, has allowed to differentiate heteroplasmy from homoplasmy $[8,16]$. According to our DGGE

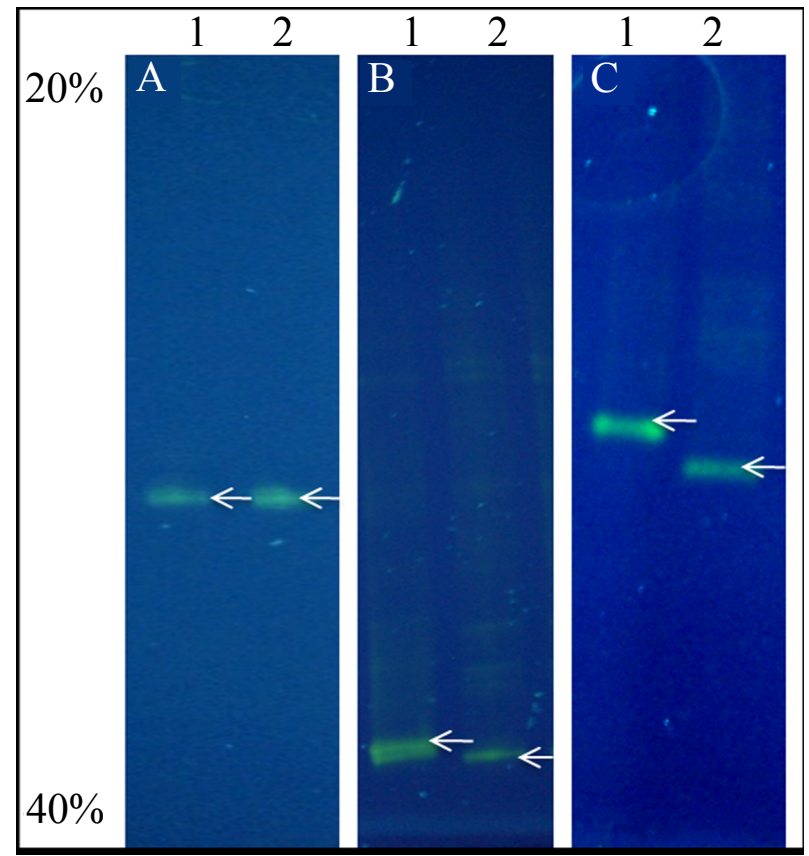

Figure 1: DGGE analysis of different $P C R$ fragments used in partial sequence of $12 \mathrm{~S}$ rRNA mitochondrial gene. A) Unclamped GC; B and C) GC-clamped. Lane 1: no mutant. Lane 2: T1189C Arrows indicate the differences in migration. results, the 1189C change seems not to be a mismatch and it is indeed a homoplasmic mutation. The precision (repeatability) was determined by the analysis in duplicate samples of 2 carried out under the same operating conditions which had the exact same electrophoretic behavior corresponding to their sequencing thus demonstrating the acceptable repeatability of the method.

Finally, optimal conditions of the method were: a denaturing gradient $20-40 \%$ during 4 hours and $210 \mathrm{~V}$ at $65^{\circ} \mathrm{C}$. Rigurous definition of the optimum conditions for DGGE for each fragment has permitted to implement a method for detection of T1189C in mitochondrial $12 \mathrm{~S}$ rRNA gene.

\section{Conclusions}

In this study we aimed at doing a rapid screening by DGGE of mutation $\mathrm{T} 1189 \mathrm{C}$ in the mitochondrial $12 \mathrm{~S}$ rRNA gene in blood samples of 2 hypoacusic patient treated with aminoglycosides as compared with a healthy normoacusic individual. Hereby, we show that we have optimized the method and demonstrate that it is suitable and offer uncompromised mutation sensitivity at relatively low cost with operational simplicity applicable to studies at the level of clinical laboratories. Additionally, the optimization eliminates long running times which will help to screen these mutations in a large human population with the purpose of carrier detection and to analyze whether hearing loss by aminoglycosides treatment in Mexicans is related to some mutations of mitochondrial $12 \mathrm{~S}$ rRNA gene as it has been described in other human populations, in order to making recommendations as to use an alternative treatment preventing hearing loss in an individual bearing the mutation.

\section{Acknowledgements}

Thanks are to due Dr Beatriz Aguilar Maldonado for acquisition and installation of the DGGE equipment; to Miss Aurora Castañeda for some experimenta participation and to $\mathrm{Dr}$. Carmen Tirado(INER) for patient supply. We appreciate the help of Mrs Cecilia Escalonain the laboratory and the technical personnel of the Unit of Molecular Biology (IFC-UNAM) for DNA sequencing and oligonucleotide synthesis. The careful review for English grammar correction of the manuscript by Frantz G. Israel MD is greatly acknowledged.

\section{References}

1. Granados O, Meza G (2007) A direct HPLC method to estimate streptomycin and its putative ototoxic derivative, streptidine, in blood serum: application to streptomycin-treated humans. J Pharm Biomed Anal 43: 625-630.

2. Torres-Ruiz NM, Granados O, Meza G (2011) Aminoglycosides: Therapeutics, Ototoxicity and Hypersensitivity of Mitochondrial Genetic Origin. Proc West. Pharmacol Soc 54: 48-50.

3. Hobbie SN, Bruell C, Kalapala S, Akshay S, Schmidt S, et al. (2006) A genetic model to investigate drug-target interactions at the ribosomal decoding site. Biochimie 88: 1033-1143.

4. Davies J, Gorini L, Davis BD (1965) Misreading of RNA codewords induced by aminoglycoside antibiotics. Mol Pharmacol 1: 93-106.

5. Muyzer G, de Waal EC, Uitterlinden AG (1993) Profiling of complex microbial populations by denaturing gradient gel electrophoresis analysis of polymerase chain reaction-amplified genes coding for $16 \mathrm{~S}$ rRNA. Appl Environ Microbio 59: 695-700.

6. Meza G, Torres-Ruíz NM, Aguilera P, Tirado C (2011) mtDNA mutations, hearing loss and aminoglycoside treatment in Mexicans. Braz J Otorhinolaryngol 77 : 573-576.

7. Yoon KL, Modica-Napolitano JS, Ernst SG, Aprille JR (1991) Denaturing gradient gel method for mapping single base changes in human mitochondrial DNA. Anal Biochem 196: 427-432.

8. Tully LA, Parsons TJ, Steighner RJ, Holland MM, Marino MA, et al. (2000) A sensitive denaturing gradient-Gel electrophoresis assay reveals a high frequency of heteroplasmy in hypervariable region 1 of the human mtDNA control region. Am J Hum Genet 67: 432-443. 
Citation: Torres-Ruiz NM, Meza G (2012) Rapid and Accurate Mitochondrial DNA Analysis in Amino Glycoside Sensitive Patients. Biochem \& Anal Biochem S3-002. doi:10.4172/2161-1009.S3-002

Page 4 of 4

9. Kollberg G, Jansson M, Pérez-Bercoff A, Melberg A, Lindberg C et al. (2005) Low frequency of mtDNA point mutations in patients with $\mathrm{PEO}$ associated with POLG1 mutations. Eur J Hum Genet 13: 463-469.

10. Wu Y, Stulp RP, Elfferich P, Osinga J, Buys CH, et al. (1999) Improved mutation detection in GC-rich DNA fragments by combined DGGE and CDGE. Nucleic Acids Res 27: 9.

11. Nataraj AJ, Olivos-Glander I, Kusukawa N, Highsmith WE Jr (1999) Singlestrand conformation polymorphism and heteroduplex analysis for gel-based mutation detection. Electrophoresis 20: 1177-1185.

12. Andrews RM, Kubacka I, Chinnery PF, Lightowlers RN, Turnbull DM, et al. (1999) Reanalysis and revision of the Cambridge reference sequence for human mitochondrial DNA. Nat Genet 23: 147.
13. Myers RM, Fischer SG, Lerman LS, Maniatis T (1985) Nearly all single base substitutions in DNA fragments joined to a GC-clamp can be detected by denaturing gradient gel electrophoresis. Nucleic Acids Res 13: 3131-3145.

14. Myers RM, Fischer SG, Maniatis T, Lerman LS (1985) Modification of the melting properties of duplex DNA by attachment of a GC-rich DNA sequence as determined by denaturing gradient gel electrophoresis. Nucleic Acids Res 13: 3111-3129.

15. Sheffield VC, Beck JS, Nichols B, Cousineau A, Lidral AC, et al. (1992) Detection of multiallele polymorphisms within gene sequences by GC-clamped denaturing gradient gel electrophoresis. Am J Hum Genet 50: 567-575.

16. Lo MC, Lee HM, Lin MW, Tzen CY (2005) Analysis of heteroplasmy in hypervariable region II of mitochondrial DNA in maternally related individuals. Ann N Y Acad Sci 1042: 130-135. 